\title{
The Research on the Cultivation Mode of University students' Innovative Talents Based on Innovation Competition
}

\author{
Xiang Chen \\ Hangzhou Institute of Service Engineering \\ Hangzhou Normal University \\ Hangzhou, P. R. China \\ flyingchen77@163.com
}

\author{
Yang Li \\ Hangzhou Institute of Service Engineering \\ Hangzhou Normal University \\ Hangzhou, P. R. China \\ liyangtom@163.com
}

\begin{abstract}
Innovation competition has gradually become an important carrier for the cultivation of innovative ability of college students in higher education. This paper expounds the inherent relation between innovation competition and the cultivation of college students' innovation ability, and puts forward the new model of "three points and two paths" based on innovation competition, and puts forward countermeasures and suggestions for the organization and implementation of the competition.
\end{abstract}

Keywords-innovation competition; innovation ability; talent training

\section{INTRODUCTION}

The emphasis of the development of higher education lies in the cultivation of students' innovation ability, and the innovative talents with high quality and innovation ability, which is based on the continuous conveying of the economic society. To deepen educational reform, pay attention to the spirit of innovation and the cultivation of innovative talents, is the important historical responsibility and mission of higher education [1]. However, at present, the college students' overall innovation ability is not strong. The school to the students' scientific research training starts late, the students often lack of independent thinking and innovative awareness of [2]; "transfer - Acceptance" of the traditional teaching mode to make the students' attention focus on teaching materials and examination, lack of enthusiasm, a lack of independent thinking and creative awareness [3].

In recent years, all kinds of discipline competitions in Colleges and universities flourish, through the competition, strengthen the interaction between teaching and learning, inspire students to carry out autonomous learning, training innovation, innovative thinking and innovative skills and potential. Discipline competition is conducive to the cultivation of college students innovation ability has become an indisputable fact [4].

\section{INNOVATION COMPETITION AND ABILITY}

Innovation competition is a kind of activity which is closely related to the curriculum in the classroom teaching in Colleges and universities. It is the students' comprehensive use of relevant courses to design and solve practical problems or specific problems of College Students' competition activities [5]. Currently more mature there are "National Challenge Cup competition", "National Mathematical Modeling Contest" and so on

As an effective supplement and extension of College Students' classroom theory and professional knowledge, innovation competition requires college students to understand the professional theory knowledge, and to develop innovative thinking in the process of using the logical thinking in the course of the competition. There is a natural connection between innovation competition and innovation ability training

Through the pre competition training and competition, the students' self-learning ability, thinking ability, discovery ability, aesthetic ability, especially the innovation ability of practical ability and other factors have been improved.

\section{A. Innovation contest provides an effective platform for the formation of innovation ability}

The real meaning of innovation competition is to provide students with a platform to guide students to set up innovative ideas, cultivate practical ability, improve the ability to find problems, analyze problems and solve problems. Students' participation in the process of innovation competition is a process of scientific research. In the process of analyzing and solving the problem, the students understand the basic law of scientific research activity, and learn how to analyze and deal with the problem.

Such as "Challenge Cup" which a strong comprehensive, scientific and technological content of the project a higher level of national competition, the students are required to a wide range of knowledge, practical ability. Students in the process of competition must take the initiative to learn the relevant areas of knowledge, through systematic learning, in-depth study, so as to apply knowledge to practice. This process itself is the best way to form and develop the innovation ability. 


\section{B. Innovation competition is beneficial to cultivate students autonomous learning ability}

Innovation ability is a kind of ability quality, which is based on certain theoretical knowledge, which can be applied to the practice of innovation, and can effectively mobilize the enthusiasm of students' autonomous learning. In the process of the competition, the students analyze the problem, design and make the product, meet all kinds of new problems, which requires students to study in time to supplement the lack of knowledge, in order to solve the new problems. Students improve their knowledge structure by autonomous learning, which lays a theoretical foundation for the cultivation of innovative ability.

\section{The innovation competition is helpful to explore the innovative thinking ability of College Students}

The starting point of the establishment of innovation competition lies in protecting and stimulating students' valuable creative thinking. Students as the main body of the innovation competition, from the contest theme of the determination, the pre demonstration, data collected to participate in the competition of the whole process, is an innovative thinking process. The process of creative thinking is the thinking of cultivating students' personality, process and quality formation. For each exposure innovation consciousness of students, teachers need to make the best use of the circumstances, stimulate and encourage students to form the personality of thinking and innovative ideas in the process of the competition.

\section{Innovation competition is helpful to improve students' practical ability}

The design plan to become the design of the product is the goal of innovation competition. Students through the idea, design, production of finished products, repeatedly modified, complete the operation of the work process, the minds of the creative into a real product. This is the use of theoretical knowledge to solve various problems in the actual case, the realization of the abstract thinking and image of the synchronous development, practical ability, and aesthetic quality can be improved.

\section{E. Innovation competition helps to cultivate college students' teamwork spirit}

In many innovation projects competition, the teams need work together to complete the work, in this team, everybody division of labor, carry out their duties, and help each other, to prove their team spirit. In the part of market research, the students also need to go into the field, collect material, deepen the students' understanding of the enterprise, but also to exercise the students' ability to communicate and coordinate.

\section{CONTEST MODE CONSTRUCTION}

The goal of cultivating innovative talents in Colleges and universities is cultivating a man with moral ,wisdom, physical , and virtue, it also has a solid foundation, wide range of knowledge, ability, quality high, with innovative talents with innovation spirit and practice ability strong. Therefore, the overall design of innovative talents training mode should follow the principle of "strengthening the foundation, highlighting the innovation consciousness and innovation ability, strengthening the practice, widening the specialty and improving the quality", the key outstanding innovation [7].

Based on the innovation contest "three points, two kinds of path" personnel training mode, that is, the classroom teaching, competition projects, technical training for the three basic points, the implementation of professional integration, the fund to support the two paths of innovative personnel training mode.

\section{A. Three basis points}

- Take the classroom teaching as the foundation of the innovative talents cultivation.

The main purpose of the innovation contest is to cultivate the innovation ability, but the most basic is to test the students' mastery of basic theory, basic knowledge and skills. Classroom teaching is the main way to obtain and form knowledge, theory and skills. Therefore, it is necessary to give full play to the basic role of classroom teaching in the cultivation of innovative talents. In curriculum design, we should pay attention to the arrangement of basic course, highlight the importance of practical teaching, make sure to choose elective courses, and to cultivate students' ability of active learning and scientific thinking, which embodies the idea of "people-oriented".

- Take the competition project as the carrier of innovative talents cultivation.

Each contest project is a practical process for the understanding of the knowledge, the system to organize and the creative play [8]. All kinds of innovation competition in the close combination of classroom teaching based on the way of competition to stimulate students to contact the actual and independent exploration of the power, through the discovery of problems, solve problems, to cultivate students' learning interest, Reinforcement learning's self-confidence, is an effective way to cultivate innovative ability. Therefore, it is needed to establish and improve the project system of innovation competition by combing the category of various kinds of competitions, and establishing and perfecting the project system of innovation competition.

- Let the technical training as a means of cultivating innovative talents.

The creative improvement is the result of the simultaneous development of knowledge, skills and strategies [8]. Through the process of cultivating innovation ability of innovation contest, it is the theory of students' comprehensive school, and the process of solving the problem creatively. The most important is Technical solutions. Therefore, it is necessary to strengthen the technical training in the competition, which is the core of the students' innovation ability.

Three basic points of classroom teaching, competition and technology training are closely related to each other, and it also independent From different angles and stages, they provide support for the cultivation of college students innovation ability, and the interaction between the three, together constitute a 
relatively complete and three-dimensional system of innovative ability training.

\section{B. The Two paths}

- Path one, professional integration and promote innovation.

For example, the students for the 2009 level of liberal arts students, after the transfer into software engineering, 2013 computer science and technology professional.

From the beginning, the students try to break through the shackles of the professional, and integrate into the atmosphere of the school innovation competition. Liberal arts classes for her to lay a foundation for the liberal arts, into the software engineering professional, a large number of simulation competitions for the creation of a good practice environment. For different professional knowledge fusion to enable her to ease will master the knowledge applied to practice, and accumulated rich experience in the competition and training to develop the innovative consciousness and competition of interest.

- $\quad$ Path two,fund support and promote development.

Zhou, the student of 2008 grade electronic information professional students, 2012 computer science and technology professional graduate students.

Zhou in undergraduate and graduate post-graduate stage, hosted and participated in a four student innovation fund project, participated in the sand table simulation contest, business plan competitions and other academic competitions, and in 2012 as one of the four respondents obtained the eighth "Challenge Cup" National University Business Plan Competition silver. Various disciplines and innovative competition training of a week of innovation and innovation ability, so that it can quickly enter the research state and in the international and domestic authoritative journals published several papers, the results achieved are due to his participation in innovation and competition.

The growth of the two students in the case has benefited from the mechanism of the cultivation of outstanding talents. Because the wealth of competition and business experience, Zhou learn the different professional knowledge integration, promotion of learning ability and ability to innovate; the case of a week through a solid scientific research foundation, innovation fund projects as the basis, exercise their own academic innovation. all roads lead to Rome, Both business practice, competition training or research project. "integration of professional, fund to support" the combination of two kinds of path of talent training mode to develop the students' creative thinking, to promote the rapid growth of the students.

\section{COUNTERMEASURES AND SUGGESTIONS}

\section{A. Establish corresponding safeguard mechanism}

Perfect safeguard mechanism to ensure that the innovation competition science and good operation. The establishment and improvement of the protection mechanism mainly includes the following 5 aspects.
- System construction and standardization management. The innovation competition system construction in the higher education system system, becomes the system, the routine work. Under the current education system, the innovation competition does not belong to the teaching plan, teachers' workload in the competition is difficult to be included in the workload assessment, various kinds of competitions, students also difficult to participate in, we need to establish a sound management system for college innovation, competition projects for screening and standardization of process management, to provide support for the innovation of scientific development.

- Guide teachers team construction. To guide teachers is an important guarantee for students to participate in all kinds of innovation competitions, we must establish a strong business, high quality, experienced professional guidance teachers.

- Teaching conditions and resources. Strengthen laboratory, innovative training base construction, and make full use of all kinds of laboratories, libraries, engineering training center and other existing resources, in order to ensure the normal teaching, as far as possible to serve the innovative competition activities, and actively play the role of the school science and Technology Park, practice base and other teaching resources, to provide favorable conditions for innovation.

- The creation of environmental atmosphere. Strengthen scientific and technological innovation in the construction of campus culture, and actively organized the forum, seminars, salon, science and technology festival, etc., to strengthen the construction of style of study, and create an atmosphere to encourage innovation.

- Perfection of financial security mechanism. Set up special funds for competition, for organizing competitions and award winning students and teachers, standardize the management of the use of funds, the project responsible person in charge and the ensuring earmarking.

\section{B. Establish incentive and restraint mechanisms}

Participating in the contest for the teachers and students means more time and energy, but also need to take the risk of losing the game. It is necessary to establish and perfect the mechanism of rewards and punishment in the interests of the rights of responsibility, and encourage the majority of teachers and students to actively participate in the work. The reform of the current evaluation mechanism can be included in the assessment of teaching workload of teachers, and performance assessment, professional title evaluation, bonus income, etc., for outstanding students in the innovation competition, in addition to the award of honor and material reward, can be recommended to graduate students, recommended employment and other aspects of the appropriate policy tilt, to provide security for the healthy development of innovation. 


\section{Establish an effective mechanism for the transformation of results}

To establish an effective mechanism for promoting the sustainable development of innovation competition, the use of the results of the display to play the diffusion effect can better promote the development of innovation competition. Schools need to establish and improve the conversion mechanism for outstanding scientific research work to provide the channels, such as papers published, patent applications, the excellent program can be transformed into practical teaching case; innovation competition in the outstanding products, can be through the exchange and cooperation between the various channels, and to have practical application value of the project, to achieve its value to promote economic and social development.

\section{CONCLUSION}

Over the years, through all levels of the educational reform projects, we put academic competitions and talent training as the research focus, and strive to explore the scientific and practical discipline competition training plan, through the universal law of the study subject contest to re-examine the shortcomings in the planning of our culture, in accordance with the concept of innovative talent training of the "three basis points, two paths", we have obtained the excellent result.

\section{REFERENCES}

[1] Shuibin Zeng. From "engineering education" to "cultural education"--Rethinking on the cultivation of innovative talents in Universities. Jiangsu higher education,2014,(5).

[2] Yingying Dong. About the Chinese University Students' practical ability and the cultivation of research [D]. East China Normal University, 2007.

[3] Dong Jian, Guo Ying. To promote the reform of undergraduate training mode (J). Experimental technology and management, 2013, (8):30.

[4] Liang Huakui (4) is an important carrier for the cultivation of innovative talents. Journal of Hubei University of Education, 2010, 27 (9):45.

[5] Peter Chang, Qingxian Wu. International Collegiate Programming Design Competition and innovation talent culture $[\mathrm{J}]$. Electrical and electronic teaching journal, 2008, (6): 44-45.

[6] Liu Wei. Research on the positive effect of science and technology competition on the development of College Students' innovative thinking. Taiyuan University of Science and Technology, 2013.

[7] Zhu Hong. Exploration and practice of innovative talents training mode in Colleges and universities (J). University education management, 2008, (5): 6

[8] Guofeng Li, et al. On the training mode of college students innovation ability cultivation model of college students based on subject contest (J), 2013, (3): 78-79. 